
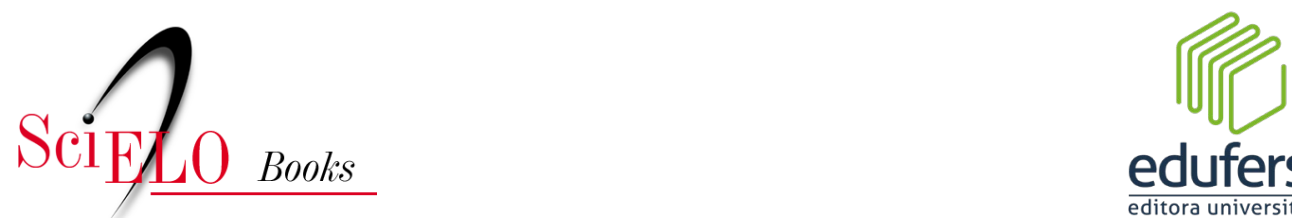

edufersa

editora universitária

\title{
8 - Ontohedu: uma ontologia para subsidiar a aprendizagem no campo de educação patrimonial
}

\author{
Ramiro de Vasconcelos dos Santos Júnior \\ Gerciane Maria da Costa Oliveira \\ Francisco Milton Mendes Neto \\ Salatiel Dantas Silva \\ Igor Fernandes dos Santos \\ Ademar França de Sousa Neto
}

\section{SciELO Books / SciELO Livros / SciELO Libros}

JÚNIOR, R. V. S., OLIVEIRA, G. M. C., MENDES NETO, F. M., SILVA, S. D., SANTOS, I. F., and SOUSA NETO, A. F. S. Ontohedu: uma ontologia para subsidiar a aprendizagem no campo de educação patrimonial. In: OLIVEIRA, G. M. C., and VIEIRA, K. M. A., eds. Patrimônio, povos do campo e memórias: diálogos com a cultura, a arte e a educação [online]. Mossoró: EdUFERSA, 2020, pp. 123-135. ISBN: 978-65-87108-09-4.

https://doi.org/10.7476/9786587108605.0009.

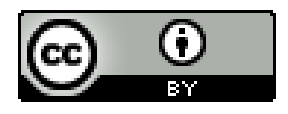

All the contents of this work, except where otherwise noted, is licensed under a Creative Commons Attribution 4.0 International license.

Todo o conteúdo deste trabalho, exceto quando houver ressalva, é publicado sob a licença Creative Commons Atribição 4.0. 


\section{ONTOHEDU: UMA ONTOLOGIA PARA SUBSIDIAR A APRENDIZAGEM NO CAMPO DE EDUCAÇÃO PATRIMONIAL}

Ramiro de Vasconcelos dos Santos Júnior Gerciane Maria da Costa Oliveira

Francisco Milton Mendes Neto

Salatiel Dantas Silva

Igor Fernandes dos Santos

Ademar França de Sousa Neto

\section{Introdução}

O campo da cultura tem passado por um processo de informatização. Com isso, tem gerado um grande volume de dados no ambiente virtual, tornando importante buscar meios para divulgar e apropriar-se deste material. De acordo com Nakagawa et al. (2013), na procura de abertura para estudos relacionados à organização do conhecimento e novas tecnologias para a representação e recuperação da informação há uma necessidade de desenvolver padrões de organização dessa informação. Ainda dentro do contexto, sobre informatização, tem-se a necessidade de pensar em acesso qualificado.

O domínio patrimônio arqueológico, ramificação do amplo campo da cultura que constitui o domínio desta pesquisa, suscita a promoção da educação patrimonial que, de acordo com Grunberg (2007), entende-se por um processo contínuo e metódico de trabalho educativo, que tem como centro o patrimônio cultural e todas as suas manifestações. A partir do conceito de educação patrimonial, foi realizado um estudo sobre o Lajedo de Soledade, estudo de caso desta pesquisa. O Lajedo é um sítio arqueológico 
que segundo Porpino, Santos e Bergqvist (2004), é um dos sítios arqueológicos mais importantes do Brasil. De acordo com Spencer (2010), somente o Lajedo de Soledade está protegido e preservado por instituição privada, a FALS ${ }^{28}$, e cumprindo sua função social de referência cultural.

Dada essa relevância, surge o interesse de se estudar o acervo referente ao patrimônio deste lugar. Para mapear todo o acervo e disponibilizá-lo para o público (escolar e não escolar), foi desenvolvida uma tecnologia capaz de armazenar todos os dados, inferi-los e, posteriormente, por meio deles, gerar conhecimento. $\mathrm{O}$ aparato tecnológico que viabilizou esta problemática foi a especificação de uma ontologia. O termo ontologia é um conceito bastante abordado dentro da Filosofia e, segundo Almeida e Bax (2004), tem por instrumento o estudo das características mais gerais do Ser, das coisas, tais como em si mesmas, reais e verdadeiras. Dentro do contexto computacional, ontologias capturam conhecimentos sobre um domínio específico que esteja sendo pesquisado e são usadas para representar as implicações semânticas necessárias para o suporte de raciocínio decidível (PAI; HSU; CHUNG, 2016).

Cada vez mais, as ontologias vêm conquistando um espaço dentro do campo de pesquisas, principalmente, em áreas como Ciência da Computação, mais especificamente na parte de inteligência artificial. Esta tendência é justificada pela capacidade que as ontologias ofertam para a organização da informação e a possibilidade de estruturação do conhecimento de um certo domínio (OYOLA; ALVARENGA, 2012). Para o campo da cultura, com as informações que já existem, as ontologias são capazes de recuperá-las e assim permitir o planejamento de novas ações. Outra vantagem é que podem ser construídas de forma colaborativa, representando e planejando ações culturais de uma maneira consistente e constante.

28 Fundação dos Amigos do Lajedo de Soledade - FALS, entidade privada que tem como objetivo principal proteger, regulamentar e monitorar as visitas de turistas e estudantes ao sítio arqueológico. 


\section{Teoria que fundamenta este trabalho}

Esta seção subdivide-se em três partes: A primeira subseção refere-se à relação da cultura com as tecnologias de informação e comunicação (TICs). A segunda subseção trata dos conceitos relacionada à educação patrimonial. A terceira e última subseção é abordado o conceito de ontologias.

\section{Cultura e sua relação com as TICs promovendo educação patrimonial}

Há estudos mostrando que nos próximos 15 anos a tecnologia passará por grandes transformações, as quais poderão ser alavancadas para a educação (SHULER; WINTERS; WEST, 2014). Em meio a estas transformações e inovações tecnológicas, alunos ou usuários quaisquer poderão coletar dados sobre suas práticas, disseminar e argumentar as informações com professores, tutores, mentores e até mesmo os próprios colegas.

Devido à amplitude do termo cultura, o enfoque é voltado para sua aplicação dentro do contexto relacionado às TICs. Com isso, é necessário levar em consideração sua importância para com a sociedade e, deste modo, é primordial pensar em adaptações que relacionam essas questões culturais ao mundo digital (WALKER, 2010).

Dentro do espaço cultural há alguns desafios importantes, dentre os quais tem-se o suporte a usuários e a forma de gerenciar o conhecimento cultural. Este último se determina por meio do formato em que se projeta TICs interoperáveis e não invasivas. Está bem comum o acesso ao conhecimento tanto próximo ao espaço físico-geográfico quanto próximo ao espaço conectivo de uma rede comunicativa e dilatada que só a mobilidade da cultura digital pode oferecer (MELO; BOLL, 2014).

Almeida (2014) explica que há dois aspectos em relação ao papel da cultura: de um lado como fonte de criação e crítica social; de outro, como possibilidade de afirmação e adesão ao sistema, na forma de atividade econômica e geração de recursos cada vez mais relevantes. Este modelo faz perceber um ambiente provido pelas TICs, uma vez que estas acabam estabelecendo uma espécie de rede global. Dessa forma, Knobel e Lankshear (2007) definem que o acesso às tecnologias digitais pode possibilitar a 
descentralização do conhecimento, a diversidade e a promoção da colaboração entre os sujeitos produtores de cultura e da transformação social, denominando assim como um novo ethos.

Esta lógica acaba norteando a relação cultura e tecnologias para questões que envolvem política e economia (HALL, 2006). Segundo Almeida (2014), às políticas culturais envolvem instituições como governos, ONGs e associações a aparatos infraestruturais e agentes humanos como gestores, técnicos e usuários, nos mais diversos níveis.

\section{Conceitos relacionados à Educação Patrimonial}

Segundo Mendoza, Baldiris e Fabregat (2015), a educação patrimonial pode ser considerada como um processo pedagógico no qual as pessoas são capazes de aprender sobre os bens patrimoniais. Grunberg (2007) define patrimônio cultural como todas as manifestações e expressões que grupos sociais criam e se acumulam ao longo dos anos com as das gerações anteriores e é possível trabalhar em um processo constante de conhecimento e descoberta a partir do patrimônio material e imaterial.

Deparar-se com o problema referente à educação patrimonial faz com que se busque meios que conduzam a uma solução. Esses meios estão nas tecnologias emergentes que abrem diversos leques de opções relacionados aos problemas supracitados. A ideia é que, por intermédio dessas tecnologias, seja possível transmitir tais conteúdos adiante e que estes possam produzir ensino-aprendizagem, tanto por meio formal quanto informal.

É interessante que a educação e a tecnologia possam caminhar juntas, traçando paralelos de desenvolvimento que possam servir de apoio uma à outra. De acordo com Shuler, Winters e West (2014), com os incentivos políticos e sociais certos, e o que é mais urgente, como os mecanismos de capacitação para a formulação de intervenções de aprendizagem é possível ter o potencial necessário para transformar as oportunidades e os resultados educacionais. 
Embora a educação sobre o patrimônio seja frequentemente um processo aberto em instituições formais, as novas gerações não são motivadas por ações culturais públicas a conhecerem ou a produzir conhecimento sobre os valores do patrimônio em relação aos lugares que habitam devido à globalização e às influências culturais de outros países.

\section{Conceitos relacionados às Ontologias}

Ontologia é um termo que advém da Filosofia. Muito embora este termo possua mais de uma vertente de pensamento. Assim, ontologia pode ser estabelecida como Estudo do Ser, ou estudo da natureza do ser, da existência ou realidade que estuda os tipos de coisas que existem no mundo (ALMEIDA; BAX, 2004). De acordo com os autores, este termo tem origem no grego "ontos", ser, e "logos", palavra e que pode ser usada para classificar alguma coisa. Em relação ao contexto computacional, há diversas definições sobre ontologias.

Segundo Kobashi (2009), pesquisadores da área de inteligência artificial adotam o uso desta técnica como forma de aprimorar os meios de categorização e representação das informações. Freitas (2003) destaca que há diversas vantagens de se utilizar ontologia. De acordo com o autor, elas são interessantes de serem utilizadas em sistemas que têm como foco o ensino por auxiliarem na representação do conhecimento de modo formal e completo, além de ser um conceito maduro e possuir ferramentas bem trabalhadas que auxiliam a empregar o conceito.

\section{Ontohedu e webhedu como solução tecnológica}

Nesta seção é possível entender como é o funcionamento da aplicação desenvolvida, sua arquitetura, bem como os elementos para a especificação da ontologia. Esta última deverá mapear o conhecimento existente no sítio arqueológico Lajedo de Soledade, local a que esta pesquisa se agrega. Para integração com a ontologia foi desenvolvido um sistema de informação que poderá ser usado por meio da plataforma Web. 


\section{Sítio Arqueológico Lajedo de Soledade}

É importante destacar o Lajedo de Soledade, uma vez que este é um dos propósitos deste capítulo. O sítio arqueológico e o Museu ficam localizados na comunidade de Soledade, distante $12 \mathrm{Km}$ de Apodi/RN e aproximadamente $76 \mathrm{Km}$ de Mossoró/RN. A cidade de Apodi possui uma área territorial de 1.602,77 km2, com população estimada em 36.323 pessoas (IBGE, 2017). Ela fica a $340 \mathrm{Km}$ da capital do estado norte-rio-grandense, Natal/RN, e a $323 \mathrm{Km}$ da capital cearense, Fortaleza/CE.

Segundo Bagnoli (1994), o Lajedo de Soledade é considerado como a maior exposição de rocha calcária da Bacia Potiguar que se formou há 90 milhões de anos, quando um mar raso cobria a região, formando ravinas e cavernas. Segundo Alves (2016), a geologia que domina no sítio arqueológico Lajedo de Soledade é o calcário Jandaíra e o relevo é predominantemente plano, exceção às diversas ravinas derivadas de processos de intemperismo.

Com relação às ravinas, Franco (2015) explica que elas são formadas por meio do processo de erosão hídrica, o qual desencadeia alterações da estrutura do solo, provocando assim uma incisão na superfície da pavimentação. Na Figura 1 é ilustrada uma divisão (por áreas) onde se encontram essas ravinas.

A OntoHedu foi especificada para mapear o conhecimento a partir do domínio proposto como estudo. Assim, ela servirá como base de conhecimento para subsidiar a aprendizagem no campo escolar e não escolar. Com isso, é relevante que se possa adquirir conhecimento por meio dos elementos encontrados no Lajedo de Soledade.

\section{Arquitetura Geral}

Como solução tecnológica para esta pesquisa, a arquitetura foi dividida em três partes: a OntoHedu como base de conhecimento, a base de dados e a WebHedu como aplicação Web. Para armazenamento, tem-se a camada de base de conhecimento, na qual conterá a ontologia voltada para educação patrimonial, especificada a partir do domínio patrimônio arqueológico. Também para a parte de armazenamento, uma base de dados 
Figura 1 - Áreas do Sítio Arqueológico Lajedo de Soledade
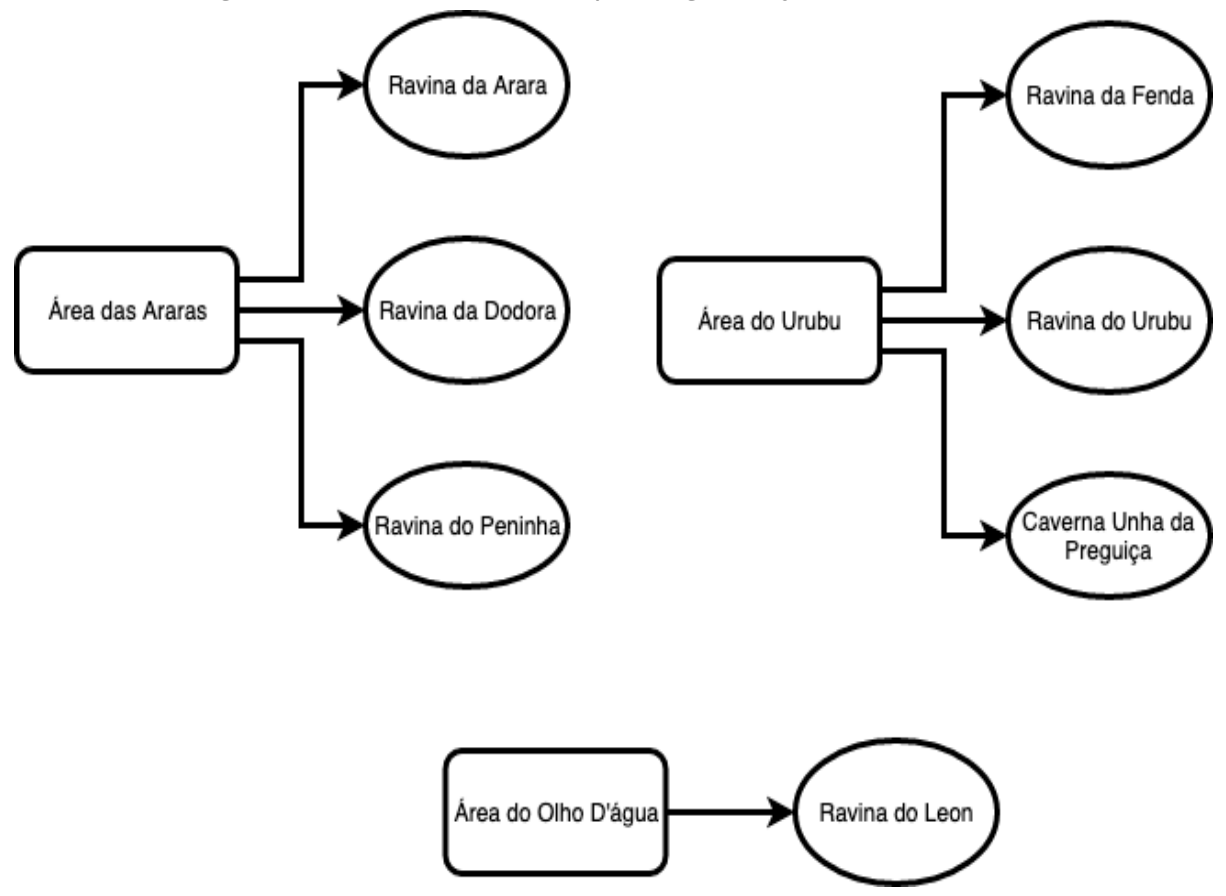

Fonte: Autoria própria (2019).

para armazenar os cadastros de especialistas que terão acesso específico e diferente dos usuários comuns.

Os elementos que serão inseridos estão classificados como: (i) inscrições rupestres, (ii) fragmentos cerâmicos e seus processos de manufatura e técnicas de decoração plástica, (iii) ferramentas pré-históricas, (iv) fragmentos de fósseis animais advindos da megafauna, bem como sua geodiversidade. Como forma de acesso às informações armazenadas na ontologia, utiliza-se a WebHedu. Todo esse ecossistema é fundamental para a área de educação patrimonial. Na Figura 2 é ilustrada a visão geral da aplicação. 
Figura 2 - Visão Geral da Aplicação

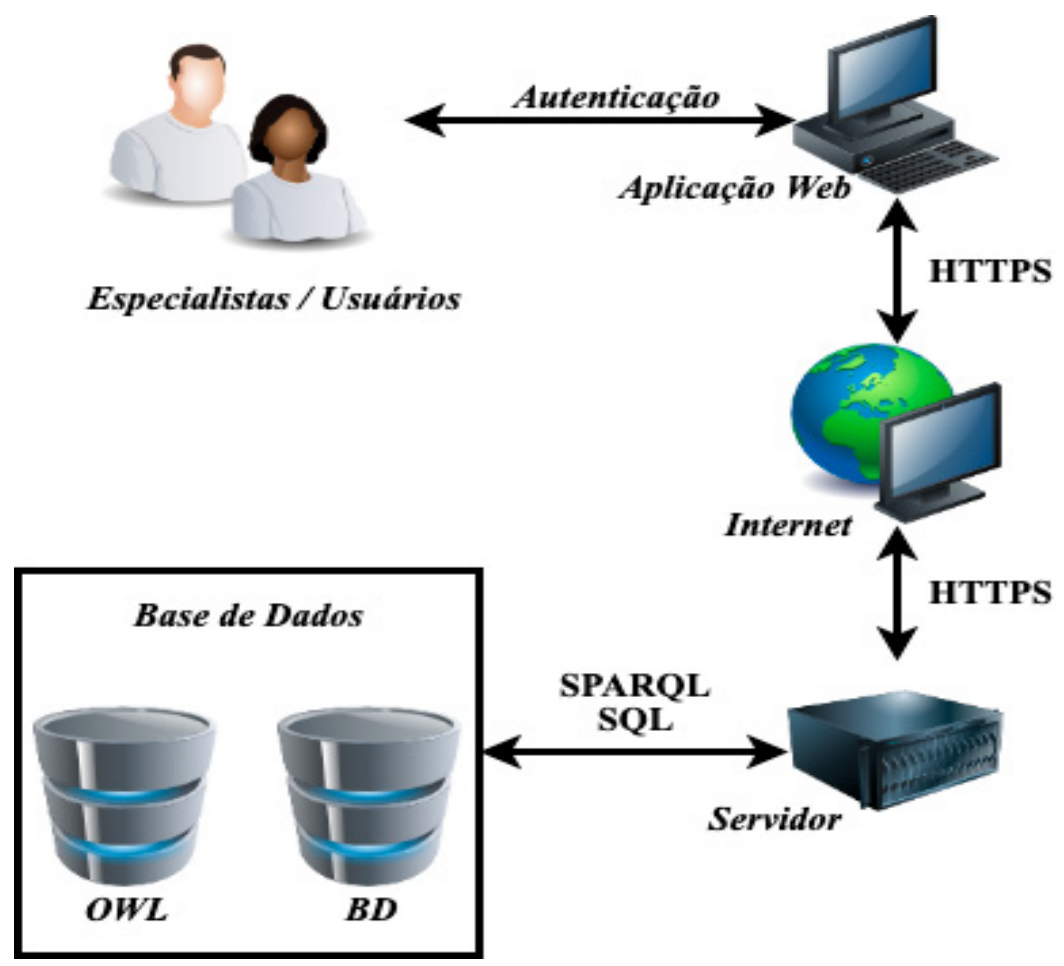

Fonte: Autoria própria (2019).

A arquitetura seguiu o padrão de projeto MVC (Modelo-VisãoControle) apresentado por Gamma (1995), um padrão usado para desenvolvimento Web.

\section{Processo de Utilização da WebHedu}

Inicialmente, para acesso privilegiado, no qual é possível inserir/atualizar informações na OntoHedu por meio da WebHedu, é necessário que um especialista realize um login com seu e-mail e uma senha. Uma vez que esta aplicação esteja sob responsabilidade da instituição, um administrador será encarregado de controlar os especialistas que terão acesso à aplicação. Como já mencionado, esses especialistas poderão ser professores, pesquisadores, bem como os guias turístico do Lajedo de Soledade. 
Antes de poder se autenticar é necessário que o especialista tenha seu cadastro realizado, pois só assim ele conseguirá suas credenciais de acesso. Esse cadastro é inserido em uma base de dados na própria aplicação. Uma vez criado uma conta para um determinado especialista, em seguida realizado sua autenticação, o mesmo terá possibilidade de inserir um patrimônio arqueológico na OntoHedu por meio da WebHedu. Após cadastrar um patrimônio arqueológico na OntoHedu é possível visualizá-lo.

Além das informações específicas a cada artefato cadastrado, têm-se os patrimônios semelhantes. Estes são correlacionados por meio das seguintes características: tipo de patrimônio, tempo de existência e origem. A seguir será abordado todo o processo de validação desses artefatos, bem como os resultados adquiridos.

\section{Considerações Finais}

Este trabalho apresenta uma ontologia para mapear o conhecimento do sítio arqueológico e do museu do Lajedo de Soledade. Como meio para possibilitar o acesso às informações que são providas pela OntoHedu foi desenvolvida uma aplicação Web, a qual chama-se WebHedu, com a finalidade de servir de interface entre os usuários especialistas, o público não especialista e o conteúdo da base de conhecimento. Para a produção desse projeto foi utilizada a metodologia Design Science (WIERINGA, 2014). A especificação da OntoHedu seguiu as etapas da metodologia 101 proposta por Noy e McGuinness (2001), uma vez que ela possui diversos ciclos de refinamento e evolução durante o percurso do projeto de pesquisa.

O desenvolvimento deste trabalho foi norteado por uma questão geral de pesquisa: Como uma estrutura conceitual sobre patrimônio arqueológico pode subsidiar a aprendizagem para o público escolar e não escolar (aprendizagem informal) dentro do contexto de educação patrimonial? Desta forma, para solucionar esta questão, essa dissertação apresentou a OntoHedu, uma ontologia que foi especificada para subsidiar aprendizagem para educação patrimonial.

Como interface para essa base de conhecimento foi desenvolvida uma aplicação Web denominada WebHedu. Esta aplicação foi integrada à OntoHedu para que os sujeitos que a utilizarem pudessem acessar as informações 
providas pela ontologia. Em linhas gerais, os artefatos desenvolvidos visam armazenar e prover informações relacionadas às características arqueológicas do sítio Lajedo de Soledade, subsidiando aprendizagem dentro contexto de educação patrimonial.

Este trabalho apresentou a OntoHedu, ontologia que foi especificada para dar suporte à aprendizagem no campo escolar e não escolar no que diz respeito ao patrimônio arqueológico do sítio arqueológico Lajedo de Soledade por meio da aplicação Web denominada WebHedu. Sua especificação (OntoHedu) se deu por meio da metodologia 101, na qual foram seguidas as sete etapas. Desta forma, de posse das análises dos dados dos especialistas, as aplicações têm viabilidade como ferramentas de auxílio à aprendizagem e que suas intenções comportamentais de uso concluíram que pretendem usar a aplicação em suas atividades cotidianas.

Portanto, os resultados deste trabalho contribuem para inovações dentro do campo de patrimônio arqueológico promovendo aprendizagem para a área de educação patrimonial. Possibilita também expandir a ontologia especificada para outros domínios relacionados a patrimônio (por exemplo: patrimônio cultural, patrimônio rural e/ou patrimônio artístico), bem como sua influência em aspectos sociais, culturais e econômicos (como o turismo pedagógico) dentro da região. Este trabalho também pode abrir novos rumos para pesquisas interdisciplinares nas áreas de ontologias, sobretudo nas interfaces com o campo da cultura e sua vasta dimensão. 


\section{REFERÊNCIAS}

ALMEIDA, M.; BAX, M. Uma visão geral sobre ontologias: pesquisa sobre definições, tipos, aplicações, métodos de avaliação e de construção. Ciência da Informação, v. 32, n. 3, 2004. Disponível em: http:// revista.ibict.br/ciinf/article/view/984. Acesso em: 04 maio 2018.

ALMEIDA, M. A. Políticas culturais e redes sociotécnicas: reconfigurando o espaço público. Ciências Sociais Unisinos, v. 50, n. 1, 2014.

ALONSO, L. et al. Characterization of microbial community in lascaux cave by high throughput sequencing. In: EGU GENERAL ASSEMBLY CONFERENCE, 19., 2017. Abstracts [...]. [S.l.:s.n.], 2017. p. 13699. ALVES, J. J. F. Geodiversidade e geoturismo no município de Apodi/RN: o caso do lajedo de soledade. Revista de Geociências do Nordeste, v. 2, p. 1201-1210, 2016.

BAGNOLI, E. O lajedo de soledade, Apodi (RN): um exemplo de preservação do patrimônio cultural brasileiro. Revista de Arqueologia, v. 8, n. 1, p. 239-253, 1994.

BAX, M. P. A Evolução da web rumo à web semântica. Prisma. com - Revista de Ciências e Tecnologia de Informação e Comunicação, n. 19, 2017.

FRANCO, M. R. S. Formação de ravinas: significância para a perda de solo por erosão hídrica. Tese (Doutorado) - Instituto Politécnico de Bragança, Portugal, 2015. 
FREITAS, F. L. G. Ontologias e a web semântica. In: JORNADA EM INTELIGÊNCIA ARTIFICIAL, 8., 2003, [S.l.]. Minicursos [...]. [S.l.]: SBC, 2003.

GAMMA, E. Design patterns: elements of reusable object-oriented software. [S.l.]: Pearson Education India, 1995.

GRUNBERG, E. Manual de atividades práticas de educação patrimonial. Brasília: IPHAN, 2007.

HALL, S. A identidade cultural na pós-modernidade. [S.l.]: TupyKurumin, 2006.

IBGE-Instituto Brasileiro de Geografia e Estatística. Demografia do município de Apodi/RN. Rio de Janeiro: IBGE, 2017. Disponível em: https://cidades.ibge.gov.br/brasil/rn/apodi/panorama. Acesso em: 04 maio 2018.

JUSTAMAND, M.; FUNARI, P. P. A.; ALARCÓN-JIMENEZ, A. Arqueologia, turismo e história e o parque nacional Serra da CapivaraPNSC/PI. Revista Interdisciplinar Encontro das Ciências-RIEC, v. 1, n. 1, p. 1-15, 2018.

KNOBEL, M.; LANKSHEAR, C. A New literacies sampler. [S.l.]: Peter Lang, 2007. v. 29.

KOBASHI, N. Y. Fundamentos semânticos e pragmáticos da construção de instrumentos de representação de informação. DataGramaZero, Rio de Janeiro, v. 8, n. 6, 2009.

MELO, R. S.; BOLL, C. I. Cultura digital e educação: desafios contemporâneos para a aprendizagem escolar em tempos de dispositivos móveis. Revista Renote-Novas Tecnologias na Educação, v. 12, n. 1, p. 1-11, 2014.

MENDOZA, R.; BALDIRIS, S.; FABREGAT, R. Framework to heritage education using emerging technologies. Procedia Computer Science, v. 75, p. 239-249, 2015. 
NAKAGAWA, E. Y. et al. Fazendas históricas paulistas dos séculos XVIII e XVX: premissas teóricas e metodológicas para inventariar bens patrimoniais. Resgate, 2013.

NOY, N. F.; MCGUINNESS, D. L. Ontology development 101: a guide to creating your first ontology. [S.l.]: Stanford, CA, 2001.

OYOLA, A. V.; ALVARENGA, L. Mapeamento e representação do conhecimento e modelagem ontológica: uma experiência na área da cultura do sorgo. Belo Horizonte: UFMG, 2012. Disponível em: https:// bit.ly/3bTFH1R. Acesso em: 12 set. 2020.

PAI, F.-P.; HSU, I.-C.; CHUNG, Y.-C. Semantic web technology for agent interoperability: a proposed infrastructure. Applied Intelligence, v. 44, n. 1, p. 1-16, 2016.

PORPINO, K. d. O.; SANTOS, M.; BERGQVIST, L. Registros de mamíferos fósseis no Lajedo de Soledade, Apodi, Rio Grande do Norte, Brasil. Revista Brasileira de Paleontologia, v. 7, n. 3, p. 349-358, 2004.

SHULER, C.; WINTERS, N.; WEST, M. 0 futuro da aprendizagem móvel: implicações para planejadores e gestores de políticas. Tradução de Cecile Vossenaar. Brasília: Unesco, 2014.

SPENCER, W. B. O Patrimônio cultural desconsiderado: o Lajedo de Soledade. Mneme-Revista de Humanidades, v. 6, n. 13, 2010.

WALKER, K. Designing for meaning making in museums: visitorconstructed trails using mobile digital technologies. Tese (Doutorado) University of London, 2010.

WIERINGA, R. J. Design Science Methodology for Information Systems and Software Engineering. [S.l.]: Berlin: Springer, 2014. 